\title{
Preface: Climate Change Impact on Plant Ecology
}

\author{
Marcello Vitale ${ }^{1, *(\mathbb{D}}$ and Alessio Collalti ${ }^{2,3}$ (1) \\ 1 Department of Environmental Biology, Sapienza University of Rome, 00185 Rome, Italy \\ 2 Institute for Agriculture and Forestry Systems in the Mediterranean, National Research Council of Italy, \\ 87036 Rende (CS), Italy; alessio.collalti@cnr.it \\ 3 Department of Innovation in Biological, Agro-Food and Forest Systems, University of Tuscia, \\ 01100 Viterbo, Italy \\ * Correspondence: marcello.vitale@uniroma1.it
}

Received: 22 April 2020; Accepted: 23 April 2020; Published: 25 April 2020

check for updates

Climate change likely represents the major modifying agents of functional and structural processes in terrestrial and marine ecosystems. Its importance lies in the fact that the space-time dynamics through which it acts on environmental systems are scale dependent and, consequently, the responses are also dependent on the space scale. Writing, therefore, on the impact of climate change on the ecology of plant species is certainly a tremendous-highly timely — challenge. This is also given the huge collection of studies that have analysed the consequences of climate change as specific effects on plant species and plant communities. Many studies have been conducted so far on the alteration of primary productivity, which is so important in the economic evaluation of the effects of climate change on agricultural species, but also on forest ecosystems, where the damage caused by environmental pollution has also been exacerbated by sudden changes of climatic parameters. As a consequence of the, only apparently, chaotic behaviour of the climate, the effects on photosynthetic activity and primary productivity are different at the various latitudes and longitudes of the planet. In fact, globally, greening trends (the increased photosynthetic activity in vegetation over time) have significantly increased over the last two-three decades by 22-33\%, particularly over China, India, many parts of Europe, central North America, southeast Brazil, and southeast Australia [1]. This also results from a combination of direct factors, i.e., land use and management, forest conservation, and expansion, and other indirect factors, i.e., increased atmospheric carbon dioxide concentration and its relative fertilisation effect, extended growing season, global warming, nitrogen deposition, and an increase in diffuse radiation [2-6]. Such factors are, to a variable extent, linked to human activities. Agriculture, forestry and other land use (AFOLU) are a significant net source of greenhouse gas (GHG) emissions, contributing to about $23 \%$ of anthropogenic emissions of carbon dioxide $\left(\mathrm{CO}_{2}\right)$, methane $\left(\mathrm{CH}_{4}\right)$ and nitrous oxide $\left(\mathrm{N}_{2} \mathrm{O}\right)$ combined as $\mathrm{CO}_{2}$ equivalents in 2007-2016. AFOLU results in both emissions and removals of $\mathrm{CO}_{2}, \mathrm{CH}_{4}$, and $\mathrm{N}_{2} \mathrm{O}$ to and from the atmosphere. These fluxes are affected simultaneously by natural and human drivers, making it difficult to separate natural from anthropogenic fluxes. The total net land-atmosphere flux of $\mathrm{CO}_{2}$ on both managed and unmanaged lands very likely provided a global net removal from 2007 to 2016 according to models of $-6.0 \pm 3.7 \mathrm{Gt} \mathrm{CO}_{2}$ year $^{-1}$ [7]. This net removal is comprised of two major components: (i) modelled net anthropogenic emissions from AFOLU are $5.2 \pm 2.6 \mathrm{Gt} \mathrm{CO}_{2}$ year ${ }^{-1}$ driven by land cover change, including deforestation and afforestation/reforestation, and wood harvesting (accounting for about 13\% of total net anthropogenic emissions of $\mathrm{CO}_{2}$ ); and (ii) modelled net removals due to non-anthropogenic processes are $11.2 \pm 2.6 \mathrm{Gt} \mathrm{CO}_{2}$ year $^{-1}$ on managed and unmanaged lands [7], driven by environmental changes such as increasing $\mathrm{CO}_{2}$, nitrogen deposition and changes in climate (accounting for the removal of $29 \%$ of the $\mathrm{CO}_{2}$ emitted from all anthropogenic activities: fossil fuel, industry, and AFOLU). The responses of vegetation and soil organic carbon (SOC) to rising atmospheric $\mathrm{CO}_{2}$ concentration and climate change are not well constrained by observations. Nutrient (e.g., nitrogen, phosphorus) availability can limit future plant growth and carbon storage under rising 
$\mathrm{CO}_{2}$. However, new evidence suggests that ecosystem adaptation through plant-microbe symbioses could alleviate some nitrogen limitation. The warming of soils and increased litter inputs will accelerate carbon losses through microbial respiration. The thawing of high latitude/altitude permafrost will increase rates of SOC loss and change the balance between $\mathrm{CO}_{2}$ and $\mathrm{CH}_{4}$ emissions. The balance between increased plant respiration in warmer climates and carbon uptake from enhanced plant growth is a key uncertainty for the size (and the sign) of the future land carbon sink (or source) capacity.

Environmental modelling with particular regard to primary producers of ecosystems and the estimation of their present and future productive potential fits into this absolutely partial framework of knowledge of the effects of climate change. The models are necessarily a simplified representation of the reality that surrounds us, but, nevertheless, they can provide scenarios useful for understanding the ecosystems' founding processes and their criticality when the pressure of environmental drivers becomes particularly strong, as we are observing right now. One of the limitations of ecological models, however, is that they depend on our level of knowledge and this is true for both theoretical and operational models. The variety and the number of ecological models is impressive, and several fields of exact sciences have been called upon to provide the technical and informatics tools that have made it possible to define their current and future developments. But even taking into consideration only a part of the ecosystem, such as the one assigned to primary production (first trophic level, photo-autotrophic compartment), our ability to simulate the processes that underlie carbon fixation in plants is limited by our current knowledge, determining a quantity of information or variability not explained by the model used, which underlies a sort of 'Uncertainty Principle' valid for the ecological sciences. The design of Nature and its state of apparent disorder at the various levels of hierarchical, spatial and temporal scales is still far from being fully discovered. Although the word 'uncertainty' resonates widely in this paper, it can represent a very key source of information and the force that pushes us to try other ways to increase our level of knowledge and make our simulation and forecasting ability more and more accurate in a complex world.

In this brief introduction, some aspects have been touched on that should be further explored through the papers of this Special Issue. The complexity of the real world requires us to undertake methodological approaches that are capable of integrating functional processes that operate within structures that have adapted to the external environment and simulate their adaptability to changes in time and space. As an example, the simple simulation of the trajectory of a light beam within a tree canopy collides with a structural complexity such that the model's simplifications are necessary to alleviate the computational load that would be used to trace the trajectory of the light. We need, in parallel to the biophysical and biochemical computation, new adaptive probabilistic or fuzzy logic algorithms that are able to understand the maximum variability, as is possible of the light path. Even the simple temporal dynamics of a process such as that of carbon fixation can lead to high computational difficulties when considering the self-shading of forest canopies, which varies according to the ecological status, physiology, stress, specific biodiversity, the age and position of individuals, the state of ecological succession, the spatial scale, etc. The leaf patchiness and the internal water status (water chemical potential) are functional and structural parameters that greatly influence the gas exchange both at the leaf level and at individual and community canopy levels. The models that try to simulate these processes are also limited by our mechanistic knowledge that currently is able to consider only a part of the observed variability.

Funding: This research received no external funding.

Conflicts of Interest: The authors declare no conflict of interest. 


\section{References}

1. IPCC. Climate Change and Land: An IPCC Special Report on Climate Change, Desertification, Land Degradation, Sustainable Land Management, Food Security, and Greenhouse Gas Fluxes in Terrestrial Ecosystems; Shukla, P.R., Skea, J., Buendia, E.C., Masson-Delmotte, V., Pörtner, H.-O., Roberts, D.C., Zhai, P., Slade, R., Connors, S., van Diemen, R., et al., Eds.; IPCC: Geneva, Switzerland, 2019; in press.

2. Keenan, T.F.; Riley, W.J. Greening of the land surface in the world's cold regions consistent with recent warming. Nat. Clim. Chang. 2018, 8, 825-828. [CrossRef] [PubMed]

3. Zhu, Z.; Piao, S.; Myneni, R.B.; Huang, M.; Zeng, Z.; Canadell, J.G.; Ciais, P.; Sitch, S.; Arneth, A.; Cao, C.; et al. Greening of the Earth and its drivers. Nat. Clim. Chang. 2016, 6, 791-795. [CrossRef]

4. Xu, X.; Riley, W.J.; Koven, C.D.; Jia, G. Observed and simulated sensitivities of spring greenup to preseason climate in northern temperate and boreal regions. J. Geophys. Res. Biogeosci. 2018, 123, 60-78. [CrossRef]

5. Ito, A.; Nishina, K.; Noda, H.M. Impacts of future climate change on the carbon budget of northern high-latitude terrestrial ecosystems: An analysis using ISI-MIP data. Polar Sci. 2016, 10, 346-355. [CrossRef]

6. Chen, C.; Park, T.; Wang, X.; Piao, S.; Xu, B.; Chaturvedi, R.K.; Fuchs, R.; Brovkin, V.; Ciais, P.; Tømmervik, H.; et al. China and India lead in greening of the world through land-use management. Nat. Sustain. 2019, 2, 122-129. [CrossRef] [PubMed]

7. Le Quéré, C.; Andrew, R.M.; Friedlingstein, P.; Sitch, S.; Hauck, J.; Pongratz, J.; Pickers, P.A.; Canadell, J.G.; Peters, G.P.; Arneth, A.; et al. Global Carbon Budget 2018. Earth Syst. Sci. Data 2018, 10, 2141-2194.

(C) 2020 by the authors. Licensee MDPI, Basel, Switzerland. This article is an open access article distributed under the terms and conditions of the Creative Commons Attribution (CC BY) license (http://creativecommons.org/licenses/by/4.0/). 